\title{
Estimation of stature from finger and phalange lengths in a Korean adolescent
}

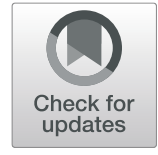

Ilsun Rhiu ${ }^{1}$ and Wonjoon $\mathrm{Kim}^{2^{*}}$ (D)

\section{Background}

The major goal of a forensic investigation is to verify identity through the victim's remains [1], which consists of individual parts of the body that are ashes, damaged, or dismembered. As such, partially damaged bodies and human remains are often encountered in fields, where intentional cutting, dismantling, explosion, or other mass disasters took place. The main purpose of investigating the damaged remains is to develop a biological profile that identifies individuals by estimating the age, gender, and stature of the remains [2, 3]. This profile helps to increase the likelihood of identifying the information of the victim's events or disasters.

Estimating statures through human remains is based on the principle that there is a linear relationship between statures and various parts of the human body and bones [4]. Previous studies that estimate statures through different parts of the body have been shown to be able to structure an estimation model with reasonable accuracy. Ahmed [5] designed a model to estimate stature and sex using upper arm length, ulnar length, and wrist breadth associated with the upper limb. Ozden et al. [6] estimated stature using the measurements of foot and shoe. Pelin et al. [7] performed a study to estimate stature from head and face dimensions. Anthropometric studies have been actively conducted to estimate statures using the upper limbs, lower extremities, and hands. Previous studies have shown that estimating statures can be more accurately estimated by using longer segments such as the upper and lower limbs of various parts of the body $[5,8]$.

However, much research has not been done to estimate statures through the fingers and phalanges. In previous studies that estimated human characteristics such as gender and stature through fingers and phalanges, Rastogi et al. [9] predicted statures through the length of the middle finger for the Indians. Kanchan and Rastogi

\footnotetext{
* Correspondence: wjkim@sungkyul.ac.kr; wjkim0114@gmail.com ${ }^{2}$ Department of Industrial and Management Engineering, Sungkyul University, Anyang 14097, South Korea

Full list of author information is available at the end of the article
}

[10] used an index and a ring finger to design a model to determine the gender of an Indian. Habib and Kamal [11] estimated stature based on the length of the hand and the length of the phalanges of each finger. Jasuja and Singh [12] estimated stature by using the measurement variables of finger and phalange of North Indian adults. Agrawal et al. [13] designed a model that estimates stature by using the length of the hand and phalanges of North Indians.

Most of the studies predicting statures by measuring fingers and phalanges were performed on adults. Krishan et al. [14] estimated stature in the northern Indian adolescent through the length of their index and ring fingers, and Ibegbu et al. [15] designed a regression model that estimated stature through the hand length in children of Nigeria. However, in many previous studies, it was confirmed that the results of stature estimation by anthropometry differed by ethnicity. Therefore, it is necessary to study the estimation of stature through the finger and phalange lengths of Korean adolescents.

From the point of view of forensic research, in case of an unresolved murder or a devastation disaster, such as a tsunami, research is needed to help estimate the stature of a person through various body parts to establish the biological profile of an unidentified individual. Especially, in case of such an affair or accident, it is difficult for the body part to be maintained in an intact state. In addition, in the case of remains caused by murder, it is likely that it has been intentionally damaged to conceal the identity of the victim. Therefore, the study of designing criteria for establishing biological profiles is very important. Based on these studies, it is possible to identify people who cannot be identified.

Most previous studies estimating stature through hand measurement related to the entire shape of the hand such as hand length and hand breadth. However, it can be difficult to get the victim's hands in intact condition at various crime scenes. In addition, research on estimating stature through various parts of the body has been conducted on various ethnicities, but only few studies were conducted on Koreans. In addition, most studies 
on Koreans, as well as other ethnic groups, have conducted adults [16]. In recent years, crimes against adolescents have been increasing, and as the methods have become diverse and cruel, research on the estimation of stature is needed.

The purpose of this study was to investigate the relationship between the stature and the length of fingers and phalanges in the Korean adolescent population. This study derives a linear regression model for stature estimation from 5 fingers and 14 phalanges. In addition, regression models with the highest prediction accuracy according to gender were derived from various regression models.

\section{Methods}

\section{Subjects}

For this study, the subjects were recruited to Koreans born in South Korea. Since there is a time-dependent variation in human stature, all measurements were made at once in the morning. Therefore, in order to unify these measurement considerations, adolescents living in Seoul, the capital of South Korea, were selected as subjects. Five subjects (males 3, females 2) with vertebral-related deformities or congenital camptodactyly were excluded from this study. Finally, a total of 172 subjects (males 89 , females 83 ) participated in the measurements, and the subjects were between 14 and 18 years of age. Their average age was 15.78 years for males $(\mathrm{SD}=1.41)$ and 15.88 years for females $(\mathrm{SD}=$ 1.46). All subjects were also right-handed for consistency of measurement. This study was approved by the research ethics committee of Seoul National University (SNUIRB no. E1505/001-002) and was, therefore, conducted according to the guidelines laid down in the Declaration of Helsinki.

\section{Measurements}

Anthropometric measurements of the statures and fingers were performed following Vallois [17]. For the consistency of measurements, finger measurements were performed on the right hand only (see Fig. 1). All measurements were made using a Martin anthropometer and a caliper in indicated by centimeters and millimeters (TTM, Japan). Information on the measurement variables for the lengths of finger and phalange is shown in Table 1 below. For stature measurement, an anthropometer was used in this study. Stature is measured as the vertical distance between the vertex point of the head and the floor surface. The subject is placed in parallel with the anthropometer and stands straight in a frontal gaze position. An investigator recorded the stature of the subjects indicated on the anthropometer. The length of the fingers was measured from the midpoint of the proximal crease of each finger to the tip of each finger using a caliper. Three types of phalange: proximal, middle, and distal were selected as the measurement variables in this study, and the method of measuring each phalange are described in Table 1.

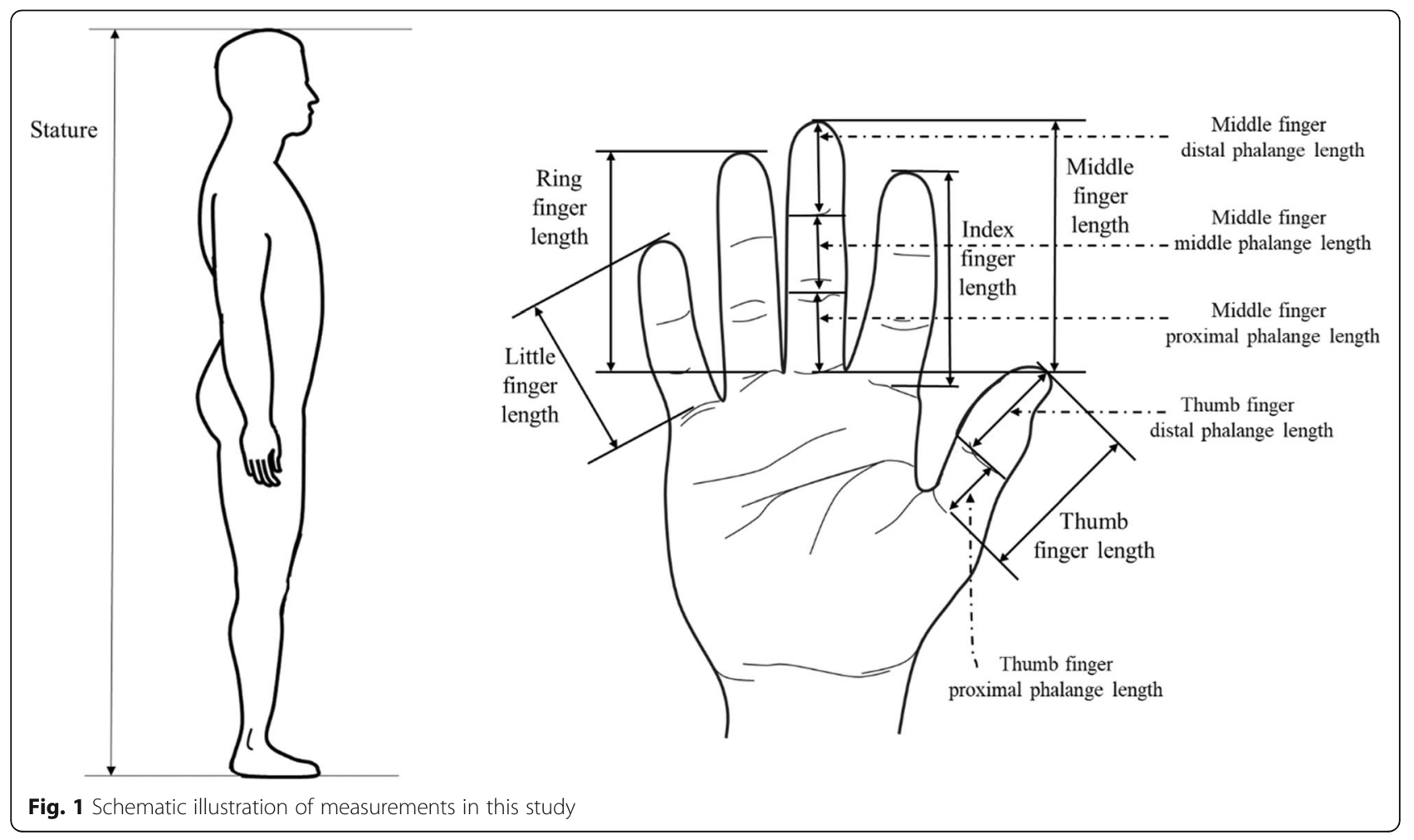


Table 1 Definition of the finger and phalange measurement [18]

\begin{tabular}{|c|c|c|c|}
\hline Category & Measurement variable & Abbreviation & Description \\
\hline Finger & $\begin{array}{l}\text { Thumb, index, middle, ring, } \\
\text { little finger length }\end{array}$ & $1 \mathrm{DL}, 2 \mathrm{DL}, 3 \mathrm{DL}, 4 \mathrm{DL}, 5 \mathrm{DL}$ & $\begin{array}{l}\text { The distance from proximal flexion crease of the } \\
\text { finger to the tip of the respected finger }\end{array}$ \\
\hline \multirow[t]{3}{*}{ Phalange } & $\begin{array}{l}\text { Thumb, index, middle, ring, little } \\
\text { finger proximal phalange length }\end{array}$ & 1DT2L, 2DI3L, 3DM3L, 4DR3L, 5DL3L & $\begin{array}{l}\text { The distance from the proximal interphalangeal joint } \\
\text { crease to metacarpophalangeal joint crease of each finger }\end{array}$ \\
\hline & $\begin{array}{l}\text { Index, middle, ring, little } \\
\text { finger middle phalange length }\end{array}$ & 2DI2L, 3DM2L, 4DR2L, 5DL2L & $\begin{array}{l}\text { The distance from the distal interphalangeal joint crease } \\
\text { to the proximal interphalangeal joint crease }\end{array}$ \\
\hline & $\begin{array}{l}\text { Thumb, index, middle, ring, little } \\
\text { finger distal phalange length }\end{array}$ & 1DT1L, 2DI1L, 3DM1L, 4DR1L, 5DL1L & $\begin{array}{l}\text { The distance from the most forwarding projecting point } \\
\text { on the tip of each finger to distal interphalangeal joint } \\
\text { crease of each finger }\end{array}$ \\
\hline
\end{tabular}

During the acquisition of the measurement data, the accuracy of the measurements was checked periodically. All measurements were performed by one trained anthropometric person. Before performing this measurement, the investigator performed preliminary measurements on 12 subjects (males $=6$, females $=6)$. Stature, finger, and phalange lengths were measured two times for each subject. Intra-observer error about each variable was measured by the technical error of measurement, relative technical error of measurement (rTEM), and coefficient of reliability $(R)$. The results are shown in Table 2 below. According to Ulijaszek and Kerr [19], if the value of rTEM is lower than $5 \%$, the intra-observer error is regarded as

Table 2 Results of TEM, rTEM (\%), $R$ calculation for each measurement variable $(\mathrm{cm})$

\begin{tabular}{llllll}
\hline Category & Mean \pm SD & & TEM & $\begin{array}{l}\text { rTEM } \\
(\%)\end{array}$ & $R$ \\
\cline { 2 - 3 } & Time 1 & Time 2 & & & \\
\cline { 1 - 3 } Stature & $167.967 \pm 8.619$ & $166.900 \pm 8.438$ & 8.052 & 0.481 & 0.991 \\
1DL & $5.835 \pm 0.585$ & $5.821 \pm 0.589$ & 0.483 & 0.829 & 0.993 \\
2DL & $6.887 \pm 0.443$ & $6.888 \pm 0.476$ & 0.656 & 0.953 & 0.980 \\
3DL & $7.722 \pm 0.467$ & $7.717 \pm 0.479$ & 0.666 & 0.863 & 0.979 \\
4DL & $7.135 \pm 0.485$ & $7.142 \pm 0.486$ & 0.617 & 0.865 & 0.982 \\
5DL & $5.662 \pm 0.366$ & $5.684 \pm 0.372$ & 0.475 & 0.837 & 0.984 \\
1DT2L & $2.870 \pm 0.490$ & $2.857 \pm 0.534$ & 0.510 & 1.781 & 0.993 \\
2DI3L & $2.274 \pm 0.199$ & $2.233 \pm 0.215$ & 0.430 & 1.910 & 0.977 \\
3DM3L & $2.596 \pm 0.237$ & $2.592 \pm 0.231$ & 0.360 & 1.389 & 0.975 \\
4DR3L & $2.192 \pm 0.344$ & $2.214 \pm 0.337$ & 0.506 & 2.298 & 0.978 \\
5DL3L & $1.754 \pm 0.197$ & $1.786 \pm 0.205$ & 0.427 & 2.412 & 0.966 \\
1DT1L & $3.089 \pm 0.226$ & $3.101 \pm 0.214$ & 0.313 & 1.011 & 0.981 \\
2DI1L & $2.216 \pm 0.194$ & $2.163 \pm 0.168$ & 0.536 & 2.449 & 0.962 \\
3DM1L & $2.608 \pm 0.245$ & $2.597 \pm 0.233$ & 0.361 & 1.386 & 0.977 \\
4DR1L & $2.352 \pm 0.185$ & $2.385 \pm 0.179$ & 0.360 & 1.522 & 0.975 \\
5DL1L & $1.598 \pm 0.144$ & $1.566 \pm 0.122$ & 0.327 & 2.070 & 0.978 \\
2DI2L & $2.424 \pm 0.213$ & $2.430 \pm 0.220$ & 0.410 & 1.690 & 0.962 \\
3DM2L & $2.494 \pm 0.234$ & $2.512 \pm 0.243$ & 0.363 & 1.448 & 0.979 \\
4DR2L & $2.523 \pm 0.253$ & $2.558 \pm 0.261$ & 0.363 & 1.429 & 0.989 \\
5DL2L & $2.285 \pm 0.176$ & $2.292 \pm 0.182$ & 0.279 & 1.221 & 0.975 \\
\hline & & & & &
\end{tabular}

an acceptable standard range for all measurements. In terms of the coefficient of reliability, Goto [20] argued that if the coefficient of reliability was above 0.95 , the quality of measurement was good controlled. Therefore, it is confirmed that the preliminary measurement result and the technical error do not affect the whole measurement, and the measured result can be considered to have reliability without significant technical and measurement error.

\section{Statistical analysis}

All statistical analyses were performed in R 3.4.4 (R Development Core Team, 2018). Gender differences in each length of finger and phalange, and stature were determined by $t$ test. Correlation between stature and each length of finger and phalange was determined through Pearson correlation coefficient. Two types of regression analysis: simple and multiple were used to estimate stature. The regression equation was used to estimate stature from the length of each finger and phalange of males and females. The stature was used as a dependent variable and the length of fingers and phalanges as an independent variable. In addition, in this study, 10-fold cross-validation was used to derive a more robust regression equation. Therefore, in this paper, the average values of coefficient of determination $\left(R^{2}\right)$, and standard error of estimate (S.E.E) derived from 10 datasets were reported. Variables with a $p$ value less than 0.05 were considered statistically significant.

\section{Results}

\section{Descriptive statistic}

The results of the descriptive statistics on the stature, finger, and phalanges between males and females are shown in Table 3 below. First, in the case of the stature, the range of males was between $152.413 \mathrm{~cm}$ and $188.368 \mathrm{~cm}$, and that of females was between $150.039 \mathrm{~cm}$ and $171.329 \mathrm{~cm}$. As can be seen in Table 3, in all measured variables, males showed higher values than females. The most significant difference between females and males was the length of the middle finger $(t=10.408)$. In the phalanges, the distal phalange of index and the distal phalange of thumb were the biggest difference $(t=8.513,8.304)$. 
Table 3 Descriptive statistics for stature, finger, and phalange length measurements $(\mathrm{cm})$ in both genders

\begin{tabular}{|c|c|c|c|c|c|c|c|c|}
\hline \multirow{2}{*}{$\begin{array}{l}\text { Measurement } \\
\text { variable }\end{array}$} & \multicolumn{3}{|c|}{ Males $(n=89)$} & \multicolumn{3}{|c|}{ Females $(n=83)$} & \multicolumn{2}{|l|}{$t$ test } \\
\hline & $\overline{\text { Mean }}$ & SE & $\overline{S D}$ & $\overline{\text { Mean }}$ & SE & $\mathrm{SD}$ & $t$ & $p$ \\
\hline Stature & 171.783 & 6.783 & 7.19 & 160.219 & 5.716 & 6.03 & 12.339 & .000 \\
\hline $1 \mathrm{DL}$ & 6.011 & 0.392 & 0.42 & 5.490 & 0.380 & 0.40 & 9.041 & .000 \\
\hline $2 \mathrm{DL}$ & 6.972 & 0.873 & 0.93 & 6.566 & 0.381 & 0.40 & 4.042 & .000 \\
\hline $3 \mathrm{DL}$ & 7.938 & 0.456 & 0.48 & 7.287 & 0.379 & 0.39 & 10.408 & .000 \\
\hline $4 \mathrm{DL}$ & 7.431 & 0.409 & 0.43 & 6.825 & 0.383 & 0.40 & 10.233 & .000 \\
\hline $5 \mathrm{DL}$ & 5.849 & 0.372 & 0.39 & 5.382 & 0.396 & 0.42 & 8.141 & .000 \\
\hline 1DT2L & 2.894 & 0.333 & 0.35 & 2.644 & 0.276 & 0.29 & 5.466 & .000 \\
\hline $2 \mathrm{DI} 3 \mathrm{~L}$ & 2.274 & 0.236 & 0.25 & 2.163 & 0.199 & 0.21 & 3.401 & .000 \\
\hline 3DM3L & 2.649 & 0.237 & 0.25 & 2.457 & 0.188 & 0.20 & 6.020 & .000 \\
\hline 4DR3L & 2.326 & 0.224 & 0.24 & 2.176 & 0.180 & 0.19 & 4.943 & .000 \\
\hline 5DL3L & 1.799 & 0.182 & 0.19 & 1.699 & 0.180 & 0.19 & 3.664 & .000 \\
\hline 1DT1L & 3.235 & 0.246 & 0.26 & 2.959 & 0.196 & 0.21 & 8.304 & .000 \\
\hline 2DI1L & 2.419 & 0.836 & 0.89 & 2.296 & 0.208 & 0.22 & 1.361 & .000 \\
\hline 3DM1L & 2.601 & 0.235 & 0.25 & 2.368 & 0.217 & 0.23 & 6.897 & .000 \\
\hline 4DR1L & 2.643 & 0.192 & 0.20 & 2.385 & 0.214 & 0.23 & 8.513 & .000 \\
\hline 5DL1L & 2.395 & 0.202 & 0.21 & 2.160 & 0.213 & 0.22 & 7.574 & .000 \\
\hline 2DI2L & 2.279 & 0.205 & 0.22 & 2.107 & 0.196 & 0.21 & 5.748 & .000 \\
\hline $3 \mathrm{DM} 2 \mathrm{~L}$ & 2.688 & 0.222 & 0.24 & 2.462 & 0.193 & 0.20 & 7.270 & .000 \\
\hline 4DR2L & 2.462 & 0.194 & 0.21 & 2.264 & 0.201 & 0.21 & 6.679 & .000 \\
\hline $5 \mathrm{DL} 2 \mathrm{~L}$ & 1.655 & 0.183 & 0.19 & 1.523 & 0.199 & 0.21 & 4.646 & .000 \\
\hline
\end{tabular}

Table 4 Pearson correlation between stature and finger/ phalange measurements in both genders

\begin{tabular}{|c|c|c|c|}
\hline \multicolumn{2}{|l|}{ Measurement variable } & \multirow{2}{*}{$\frac{\text { Males }}{.659^{* *}}$} & \multirow{2}{*}{$\begin{array}{l}\text { Females } \\
.584^{* *}\end{array}$} \\
\hline Finger & $1 \mathrm{DL}$ & & \\
\hline & $2 \mathrm{DL}$ & $.769^{* *}$ & $.536^{* *}$ \\
\hline & $3 \mathrm{DL}$ & $.701^{* *}$ & $.603^{* *}$ \\
\hline & $4 \mathrm{DL}$ & $.732^{* *}$ & $.488^{* *}$ \\
\hline & $5 D L$ & $.485^{* *}$ & $.293^{* *}$ \\
\hline \multirow[t]{5}{*}{ Proximal phalange } & 1DT2L & $.440^{* *}$ & $.452^{* *}$ \\
\hline & $2 \mathrm{DI} / 3 \mathrm{~L}$ & $.500^{* *}$ & $.333^{* *}$ \\
\hline & 3DM3L & $.544^{* *}$ & .214 \\
\hline & 4DR3L & $.503^{* *}$ & .149 \\
\hline & $5 \mathrm{DL} 3 \mathrm{~L}$ & $.258^{*}$ & .018 \\
\hline \multirow[t]{5}{*}{ Distal phalange } & 1DT1L & $.527^{* *}$ & $.477^{* *}$ \\
\hline & 2DI1L & $.446^{* *}$ & $.365^{* *}$ \\
\hline & 3DM1L & $278^{* *}$ & $.492^{* *}$ \\
\hline & 4DR1L & $.386^{* *}$ & $.444^{* *}$ \\
\hline & 5DL1L & $276^{* *}$ & $.384^{* *}$ \\
\hline \multirow[t]{4}{*}{ Middle phalange } & $2 \mathrm{DI} L \mathrm{~L}$ & $.520^{* *}$ & $.291^{* *}$ \\
\hline & 3DM2L & $.545^{* *}$ & $.387^{* *}$ \\
\hline & 4DR2L & $.555^{* *}$ & $.296^{* *}$ \\
\hline & 5DL2L & $.415^{* *}$ & .141 \\
\hline
\end{tabular}

**Correlation is significant at the 0.01 level; ${ }^{*}$ Correlation is significant at the 0.05 level
Table 5 Results of simple linear regression for estimation of stature $(\mathrm{cm})$ in males

\begin{tabular}{llll}
\hline Males & Equation & $R^{2}$ & S.E.E $(\mathrm{cm})$ \\
\hline 1DL & $S=102.377+11.540(1 \mathrm{DL})$ & .434 & 5.064 \\
2DL & $S=90.088+11.574(2 \mathrm{DL})$ & .591 & 4.308 \\
3DL & $S=88.657+10.463(3 \mathrm{DL})$ & .491 & 4.803 \\
4DL & $S=80.088+12.337(4 \mathrm{DL})$ & .536 & 4.588 \\
5DL & $S=120.045+8.834(5 \mathrm{DL})$ & .235 & 5.887 \\
1DT2L & $S=146.194+8.803(1 \mathrm{DT} 2 \mathrm{~L})$ & .193 & 6.047 \\
2DI3L & $S=139.581+14.115(2 \mathrm{DI} \mathrm{L})$ & .250 & 5.832 \\
3DM3L & $S=131.354+15.206(3 \mathrm{DM} 3 \mathrm{~L})$ & .296 & 5.649 \\
4DR3L & $S=136.661+15.067(4 \mathrm{DR} 3 \mathrm{~L})$ & .253 & 5.819 \\
5DL3L & $S=154.354+9.638(5 \mathrm{DL} 3 \mathrm{~L})$ & .067 & 6.505 \\
1DT1L & $S=125.646+14.224(1 \mathrm{DT1L})$ & .278 & 5.720 \\
2DI1L & $S=143.101+11.412(2 \mathrm{DI} 1 \mathrm{~L})$ & .199 & 6.026 \\
3DM1L & $S=150.720+8.051(3 \mathrm{DM} 1 \mathrm{~L})$ & .077 & 6.468 \\
4DR1L & $S=135.379+13.733(4 \mathrm{DR} 1 \mathrm{~L})$ & .149 & 6.209 \\
5DL1L & $S=149.693+9.168(5 \mathrm{DL} 1 \mathrm{~L})$ & .076 & 6.471 \\
2DI2L & $S=132.990+16.985(2 \mathrm{DI} \mathrm{L})$ & .270 & 5.751 \\
3DM2L & $S=127.033+16.616(3 \mathrm{DM} 2 \mathrm{~L})$ & .297 & 5.644 \\
4DR2L & $S=123.459+19.584(4 \mathrm{DR} 2 \mathrm{~L})$ & .309 & 5.598 \\
5DL2L & $S=146.758+15.039(5 \mathrm{DL} 2 \mathrm{~L})$ & .172 & 6.127 \\
\hline
\end{tabular}


Table 6 Results of simple linear regression for estimation of stature $(\mathrm{cm})$ in females

\begin{tabular}{llll}
\hline Females & Equation & $R^{2}$ & S.E.E $(\mathrm{cm})$ \\
\hline 1DL & $S=109.399+9.282(1 \mathrm{DL})$ & .341 & 4.314 \\
2DL & $S=109.385+7.757(2 \mathrm{DL})$ & .288 & 4.487 \\
3DL & $S=98.476+8.481(3 \mathrm{DL})$ & .364 & 4.239 \\
$4 \mathrm{DL}$ & $S=112.621+6.989(4 \mathrm{DL})$ & .238 & 4.639 \\
5DL & $S=138.889+3.997(5 \mathrm{DL})$ & .089 & 5.083 \\
1DT2L & $S=137.837+8.560(1 \mathrm{DT} 2 \mathrm{~L})$ & .204 & 4.743 \\
2DI3L & $S=140.863+9.036(2 \mathrm{DI} \mathrm{L})$ & .111 & 5.012 \\
3DM3L & $S=145.074+6.253(3 \mathrm{DM} 3 \mathrm{~L})$ & .046 & 5.193 \\
4DR3L & $S=150.894+4.392(4 \mathrm{DR} 3 \mathrm{~L})$ & .022 & 5.257 \\
5DL3L & $S=159.592+.518(5 \mathrm{DL} 3 \mathrm{~L})$ & .000 & 5.315 \\
1DT1L & $S=120.675+13.393(1 \mathrm{DT} 1 \mathrm{~L})$ & .228 & 4.672 \\
2DI1L & $S=138.886+9.365(2 \mathrm{DI} 1 \mathrm{~L})$ & .133 & 4.950 \\
3DM1L & $S=130.364+12.642(3 \mathrm{DM} 1 \mathrm{~L})$ & .242 & 4.629 \\
4DR1L & $S=134.033+11.036(4 \mathrm{DR} 1 \mathrm{~L})$ & .197 & 4.763 \\
5DL1L & $S=139.903+9.474(5 \mathrm{DL} 1 \mathrm{~L})$ & .147 & 4.908 \\
2DI2L & $S=143.580+8.0004(2 \mathrm{DI} \mathrm{L})$ & .085 & 5.086 \\
3DM2L & $S=133.689+10.862(3 \mathrm{DM} 2 \mathrm{~L})$ & .150 & 4.901 \\
4DR2L & $S=142.671+7.846(4 \mathrm{DR} 2 \mathrm{~L})$ & .088 & 5.077 \\
5DL2L & $S=154.795+3.723(5 \mathrm{DL} 2 \mathrm{~L})$ & .020 & 5.263 \\
\hline
\end{tabular}

\section{Correlation analysis}

There was a statistically significant correlation between the length of finger and phalange and stature. The Pearson correlation coefficients between the stature and the finger and phalange of males and females are shown in Table 4 below. In the case of males, the correlation coefficient was the highest in the index finger $(r=.769)$. The correlation coefficients of the three parts of the phalange were highest in 3DM3L, 1DT1L, and 4DR2L, respectively $(r=.544, .527, .555)$. In case of females, the correlation coefficient was the highest in the middle finger $(r=.603)$. The correlation coefficients of the three parts of the phalange were highest in 1DT2L, 3DM1L, and 3DM2L, respectively $(r=.452, .492, .387)$.

\section{Simple linear regression analysis}

In this study, the estimation of stature in Korean adolescent is performed using linear regression analysis. First, the results of simple linear regression analysis are shown in Tables 5 and 6 below. For adolescent males, index finger (2DL) $\left(R^{2}=.591\right.$, S.E.E $\left.=4.308 \mathrm{~cm}\right)$, and ring finger (4DL) $\left(R^{2}=.536\right.$, S.E.E $\left.=4.588 \mathrm{~cm}\right)$ was confirmed to be the highest determining variables in the regression equation. Among the phalanges, length of ring finger middle phalange (4DR2L) showed the highest value of the coefficient of determination $\left(R^{2}=.309\right.$, S.E.E $\left.=5.598 \mathrm{~cm}\right)$. For adolescent females, middle finger (3DL) $\left(R^{2}=.341\right.$, S.E.E $\left.=4.314 \mathrm{~cm}\right)$, and thumb finger (1DL) $\left(R^{2}=.364\right.$, S.E.E $\left.=4.239 \mathrm{~cm}\right)$ was showed to be highest determining variables in the estimation of stature. Among the phalanges, length of middle finger proximal phalange (3DM1L) showed the highest value of the coefficient of determination $\left(R^{2}=.242\right.$, S.E.E $\left.=4.629 \mathrm{~cm}\right)$.

\section{Multiple linear regression analysis}

In order to derive a regression equation with a higher coefficient of determination, multiple regression analysis was performed by combining the variables of the length of finger and phalange (Table 7). For each regression analysis, the stepwise method was used as mentioned above. First, the regression equation derived from the length of the fingers is as follows. In the case of adolescent males, the regression model consisted of three fingers (thumb, index, and ring) $\left(R^{2}=.646\right.$, S.E.E $=$ $4.055 \mathrm{~cm})$.

Next, the results of multiple regression analysis for only the phalange variables were used. In the case of adolescent males, three types of phalanges: 2DI3L, 3DM1L, and 2DI2L were included in the regression equation $\left(R^{2}=.615\right.$, S.E.E $=4.226 \mathrm{~cm}$ ). In the case of adolescent females, the coefficient of determination of the regression equation was .445 , and it was confirmed that four variables were included (3DM3L, 1DT1L, 3DM2L, and 1DT2L).

Table 7 Results of multiple linear regression for estimation of stature $(\mathrm{cm})$ from measurements

\begin{tabular}{|c|c|c|c|c|}
\hline Measurement variable & Gender & Equation & $R^{2}$ & S.E.E $(\mathrm{cm})$ \\
\hline \multirow[t]{2}{*}{ Finger } & Males & $\begin{array}{l}S=72.595+5.896(2 \mathrm{DL})+5.035(4 \mathrm{DL}) \\
+3.355(1 \mathrm{DL})\end{array}$ & .646 & 4.055 \\
\hline & Females & $S=93.653+5.895(1 \mathrm{DL})+4.704(3 \mathrm{DL})$ & .421 & 4.072 \\
\hline \multirow[t]{2}{*}{ Phalange } & Males & $\begin{array}{l}S=85.042+11.311(2 \mathrm{DI} 3 \mathrm{~L})+10.956(3 \mathrm{DM} 1 \mathrm{~L}) \\
+12.876(2 \mathrm{DI} 2 \mathrm{~L})\end{array}$ & .615 & 4.226 \\
\hline & Females & $\begin{array}{l}S=97.477+7.236(3 \mathrm{DM} 3 \mathrm{~L})+5.325(1 \mathrm{DT} 1 \mathrm{~L}) \\
+5.730(3 \mathrm{DM} 2 \mathrm{~L})+5.906(1 \mathrm{DT} 2 \mathrm{~L})\end{array}$ & .445 & 4.037 \\
\hline \multirow[t]{2}{*}{ Finger and phalange } & Males & $\begin{array}{l}S=72.739+5.798(1 \mathrm{DL})+9.639(2 \mathrm{DI} 1 \mathrm{~L}) \\
+8.724(2 \mathrm{DI} 2 \mathrm{~L})+8.105(3 \mathrm{DM} 3 \mathrm{~L})\end{array}$ & .659 & 4.004 \\
\hline & Females & $\begin{array}{l}S=89.439+6.642(1 \mathrm{DL})+9.283(4 \mathrm{DR} 1 \mathrm{~L}) \\
-10.480(5 \mathrm{DL} 1 \mathrm{~L})+4.872(3 \mathrm{DM} 2 \mathrm{~L})+8.432(3 \mathrm{DM} 3 \mathrm{~L})\end{array}$ & .529 & 3.741 \\
\hline
\end{tabular}


Finally, the results of regression equations including both the length of fingers and phalanges are shown. For adolescent males, the combination of the thumb finger length (1DL), index finger distal phalange length (2DI1L), index finger middle phalange length (2DI2L), and middle finger proximal phalange (3DM3L) derived an $R^{2}$ value of 0.659 with an average estimation error of $4.004 \mathrm{~cm}$, which was the highest coefficient of determination of the regression equation found in this study. For adolescent females, the combination of thumb finger length (1DL), ring finger distal phalange (4DR1L), little finger distal phalange length (5DL1L), middle finger middle phalange (3DM2L), and middle finger proximal phalange length (3DM3L) yielded an $R^{2}$ value of 0.529 with an average estimation error of $3.741 \mathrm{~cm}$, which was the smallest estimation error of the regression equation found in this study.

\section{Discussion}

Through this study, it was confirmed that the stature of males in Korean adolescents was statistically significantly higher than that of females. In addition, all of the lengths and phalanges of each finger was also found to be statistically significantly larger in males. A variety of previous studies of different ethnicities have shown similar results to this study. It has been reported that the hand-related measurement variables of males in Mauritius [21], North and South India, Turkey [22], Egypt [11], and Slovakia [23] are larger than those of females. According to Kanchan et al. [24], it has been confirmed that in the case of adolescents in South India, the length of ring finger in males is significantly longer than the females. Krishan et al. [14] confirmed that the length of the index and ring finger of adolescent males in North India are significantly longer than females. Most sexual size dimorphism in human statures occurs due to gender differences in growth duration and rate during adolescent growth spurts [25]. Through this study, it was confirmed that males have grown physically larger than females in Korean adolescent population.

In this study, it was confirmed that the length of the finger and phalange had a significant correlation with stature.
In a study of adolescents, Krishan reported a correlation coefficient of .748 between the index finger and stature of males and a correlation coefficient of .531 for females [14]. In previous studies that revealed the correlation between the body parts and the stature in the adolescent, Monyeki and Sekhotha [26] found that the correlation coefficients between arm span and stature of South African students aged $15-18$ years were 0.76 for males and 0.76 for females. Krishan and Kumar [27] examine the correlation between cephalo-facial measurement and stature in Koli males of North India. They found that among the various cephalo-facial measurements, horizontal circumference of head had the highest correlation coefficient with height $(r=0.773)$. Shah et al. [28] showed that there is a positive correlation between head length and stature in adolescents of West India. In case of western Indian, the correlation coefficient between stature and head length was 0.26 for males and 0.69 for females.

Similar results have been reported in studies of adults. Previous studies have been conducted to estimate statures using fingers and phalanges in adults of various ethnicities [11-13]. Rastogi et al. confirmed that there is a positive correlation between the middle finger length and the stature [9], and Jee and Yun [18] found that there is a positive correlation between each finger and the stature of Korean adults. The purpose of this comparison is to ascertain whether the correlation between stature in the adolescent population and the length of the finger and phalange is like that of the adult population in Korea. Comparing the values of the correlations measured in this study with that of Jee and Yun [18], in Korean adults, the middle finger of males and the ring finger for females were the most correlated with stature. The results showed that the degree of correlation coefficient between finger length and stature was different for adults and adolescents in Koreans. In their study, the Pearson correlation coefficient ranged from .390 to .507 for males and .375 to .465 for females. Therefore, the correlation between the length of fingers and phalanges and the stature is more significant in the adolescent populations of Koreans than in adults. This contrasts with the results of other ethnicities, especially

Table 8 Comparison of the regression equation, $R^{2}$, and S.E.E from previous studies

\begin{tabular}{|c|c|c|c|c|c|}
\hline Author & Ethnicity & Gender & Equation & $R^{2}$ & S.E.E $(\mathrm{cm})$ \\
\hline \multirow[t]{2}{*}{ Krishan et al. } & Indian (adolescent) & Males & $S=71.403+12.948(2 \mathrm{DL})$ & .560 & 5.41 \\
\hline & & Females & $S=122.437+4.559(4 \mathrm{DL})$ & .367 & 4.79 \\
\hline \multirow[t]{2}{*}{ Akhlaghi et al. } & Iranian (adult) & Males & $S=108.718+0.834(3 \mathrm{DL})$ & .454 & - \\
\hline & & Females & $S=95.058+0.901(3 \mathrm{DL})$ & .415 & - \\
\hline \multirow[t]{2}{*}{ Jasuja and Singh } & Indian (adult) & Males & $S=171.902+1.645(3 \mathrm{DM} 1 \mathrm{~L})$ & .464 & 5.40 \\
\hline & & Females & $S=152.07+3.446(2 \mathrm{DI} 2 \mathrm{~L})$ & .387 & 5.22 \\
\hline \multirow[t]{2}{*}{ Jee and Yun } & Korean (adult) & Males & $S=111.159+7.44(3 \mathrm{DL})$ & .301 & 5.34 \\
\hline & & Females & $S=107.152+6.98(4 \mathrm{DL})$ & .211 & 5.71 \\
\hline
\end{tabular}


Indians. Through this study, it was confirmed that the correlations between finger length and height of various ethnicities in adolescence were different.

Comparing the regression models derived for stature estimation in this study, it was observed that the accuracy of predicted stature estimation in both regression models was higher for males than for females. The results of this study are like those of studies conducted on various ethnicities (Table 8). In case of Korean male adolescents, the coefficient of determination of the regression equation using the hand and phalange was higher than that of adults in Egypt, India, Iran, and Korea and adolescents in India. In the case of Korean female adolescents, the coefficient of determination of the regression equation using the hand and phalange was higher than that of adults in Egypt and Korea but lower than that of India and Iran.

In forensic research, various studies have been conducted to derive a formula for estimating the stature of a specific ethnicity using a variety of anthropometric data, such as upper and lower limb, and facial measurement. Milašinović et al. [29] found that the coefficient of determination between arm span and stature of adolescents in Montenegro was 0.673 for males. According to Ibegbu et al. [15], the coefficient of determination between hand length and stature of Nigerian students was 0.498 for males and 0.494 for females. Krishan et al. [30] designed a model that estimates the stature of adolescent males in North India through the measurement variables associated with the foot length. The coefficients of determination of the models were from 0.613 to 0.666 .

Looking at previous studies, there is a lack of studies on the estimation of stature in the adolescent population. In this study, the statures are estimated only through the lengths of the fingers and phalanges, and thus cannot be directly compared with other studies. For Korean adults, the coefficient of determination of the stature estimation derived from multiple regression analysis was .425 for males and .418 for females. In this study, the values of the coefficient of determination derived from the multiple regression equation considering both fingers and phalanges were .659 for males and .529 for females, respectively. Especially, in the case of males, either the multiple regression equation derived through each finger or phalange had a higher coefficient of determination than .600 . Therefore, in the Korean population, when estimating the stature through the length of the finger and phalange, the estimation of adolescent is more accurate than the adult. In addition, previous studies conducted on Koreans, it also considered measurement variables known to be highly correlated with stature such as hand length and palm length through various studies $[3,18]$. However, in this study, only the length of the fingers and the phalange was used to design the estimation model of the stature. It can be very difficult to get the victim's hand in undamaged form at the scene of a disaster or a murder.
Therefore, it may be more effective to estimate the stature with only parts of a hand, such as the fingers and phalanges.

\section{Conclusion}

The results of this study showed that there is a statistically significant relationship between the length of the fingers and the phalanges of adolescents and the stature. According to current studies, estimating stature from the length of the fingers and phalanges is reasonably accurate compared with studies of various ethnicities and Korean adults. It has been confirmed that different results are obtained from the results of estimating statures performed for adults because adolescent has a high potential for growth. Of course, in the case of compared Korean adolescents and adults in this study, it is the limit of this study that they do not target the same person. However, this is a massive study that needs to be done over a period of 5 to 10 years. Therefore, in order to generalize this study, it is necessary to carry out a future study to compare the results after re-measuring the subjects who were selected in this study after they became adults.

When adolescents become victims of crime or disasters, estimating their height or gender can be a major criterion for identification, since their biological profiling is less complete than in adults. Thus, once the age of the victim is determined, the biological profile of the victim can be established by applying a regression model derived from this study to estimate the stature. Various kinds of method for estimating statures through body parts must be constantly studied and tested, since identifying a cadaver that is severely damaged and part of a body is a challenge for many forensic specialists. This study suggests that the possibility of estimating the stature in the incompletely cadavered fingers and phalange is left. Through the results of this study, it is expected to be used as the basic data of the studies related to finger and phalange lengths of Korean adolescents.

\section{Abbreviations \\ 1DL: Thumb finger length; 1DT1L: Thumb finger distal phalange length; 1DT2L: Thumb finger proximal phalange length; 2DL: Index finger length; 2DI1L: Index finger distal phalange length; 2DI2L: Index finger middle phalange length; 2DI3L: Index finger proximal phalange length; 3DL: Middle finger length; 3DM1L: Middle finger distal phalange length; 3DM2L: Middle finger middle phalange length; 3DM3L: Middle finger proximal phalange length; 4DL: Ring finger length; 4DR1L: Ring finger distal phalange length; 4DR2L: Ring finger middle phalange length; 4DR3L: Ring finger proximal phalange length; 5DL: Little finger length; 5DL1L: Little finger distal phalange length; 5DL2L: Little finger middle phalange length; 5DL3L: Little finger proximal phalange length; rTEM: Relative technical error of measurement}

\section{Acknowledgements}

The authors thank the administrative support from the Department of Industrial and Management Engineering at Sungkyul University.

\section{Authors' contributions}

WK conceived and designed the study, performed the experiments and the statistical analysis, and drafted the manuscript. IR helped to carry out the 
experiments and analyze the data, participated in designing and coordinating the experiment, and helped to draft the manuscript. All authors have read and approved the final manuscript.

\section{Funding}

There is no funding source for this paper.

\section{Availability of data and materials}

The datasets used and/or analyzed during the current study are available from the corresponding author on reasonable request.

\section{Ethics approval and consent to participate}

All participants gave their written informed consent after a complete explanation of this study before participating in the study. The study was performed in accordance with the guidelines of the Declaration of Helsinki and was approved by the ethics committee of the Seoul National University.

\section{Consent for publication}

None applicable.

\section{Competing interests}

The authors declare that they have no competing interests.

\section{Author details}

'Division of Big Data and Management Engineering, Hoseo University, Asan 31499, South Korea. ${ }^{2}$ Department of Industrial and Management Engineering, Sungkyul University, Anyang 14097, South Korea.

Received: 9 April 2019 Accepted: 5 September 2019

Published online: 22 October 2019

\section{References}

1. Kanchan T, Krishan K. Anthropometry of hand in sex determination of dismembered remains-a review of literature. J Forensic Legal Med. 2011; 18(1):14-7.

2. Zeybek G, Ergur I, Demiroglu Z. Stature and gender estimation using foot measurements. Forensic Sci Int. 2008:181(1):54. e1-5.

3. Kim W. A comparative study on the statistical modelling for the estimation of stature in Korean adults using hand measurements. Anthropol Anz. 2019; 76(1):57-67.

4. Krishan K, Kanchan T, Sharma A. Multiplication factor versus regression analysis in stature estimation from hand and foot dimensions. J Forensic Legal Med. 2012;19(4):211-4.

5. Ahmed AA. Estimation of stature from the upper limb measurements of Sudanese adults. Forensic Sci Int. 2013;228(1):178. e1-7.

6. Ozden $\mathrm{H}$, Balci $Y$, Demirüstü $\mathrm{C}$, et al. Stature and sex estimate using foot and shoe dimensions. Forensic Sci Int. 2005;147(2):181-4.

7. Pelin C, Zağyapan R, Yazıcı C, et al. Body height estimation from head and face dimensions: a different method. J Forensic Sci. 2010;55(5):1326-30.

8. Akhlaghi M, Hajibeygi M, Zamani $\mathrm{N}$, et al. Estimation of stature from upper limb anthropometry in Iranian population. J Forensic Legal Med. 2012;19(5):280-4.

9. Rastogi P, Kanchan T, Menezes RG, et al. Middle finger length - a predictor of stature in the Indian population. Med Sci Law. 2009;49(2):123-6.

10. Kanchan T, Rastogi P. Sex determination from hand dimensions of north and south Indians. J Forensic Sci. 2009;54(3):546-50.

11. Habib SR, Kamal NN. Stature estimation from hand and phalanges lengths of Egyptians. J Forensic Legal Med. 2010;17(3):156-60.

12. Jasuja $O$, Singh $G$. Estimation of stature from hand and phalange length. JIAMF. 2004:26(3):971-3.

13. Agrawal J, Raichandani L, Kataria SK, et al. Estimation of stature from hand length and length of phalanges. J Evol Med Dent Sci. 2013;2(50):16.

14. Krishan K, Kanchan T, Asha N. Estimation of stature from index and ring finger length in a north Indian adolescent population. J Forensic Legal Med. 2012;19(5):285-90.

15. Ibegbu AO, David ET, Hamman WO, et al. Association of hand length with height in Nigerian school children. J Biol Life Sci. 2013:4(2):83.

16. Kim W, Kim YM, Yun MH. Estimation of stature from hand and foot dimensions in a Korean population. J Forensic Legal Med. 2018:55:87-92.

17. Vallois HV. Anthropometric techniques. Curr Anthropol. 1965;6(2):127-43.

18. S-c J, Yun MH. Estimation of stature from diversified hand anthropometric dimensions from Korean population. J Forensic Legal Med. 2015;35:9-14.
19. Ulijaszek SJ, Kerr DA. Anthropometric measurement error and the assessment of nutritional status. Br J Nutr. 1999:82(3):165-77.

20. Goto R. Precision of measurement as a component of human variation. J Physiol Anthropol. 2007:26(2):253-6.

21. Agnihotri AK, Agnihotri S, Jeebun N, et al. Prediction of stature using hand dimensions. J Forensic Legal Med. 2008;15(8):479-82

22. Ozaslan A, Karadayi B, Kolusayin MO, et al. Predictive role of hand and foot dimensions in stature estimation. Rom J Leg Med. 2012;20(1):41-6.

23. Uhrová $P$, Beňuš R, Masnicová $S$, et al. Estimation of stature using hand and foot dimensions in Slovak adults. Legal Med. 2015;17(2):92-7.

24. Kanchan T, Kumar GP, Menezes RG, et al. Sexual dimorphism of the index to ring finger ratio in south Indian adolescents. J Forensic Legal Med. 2010; 17(5):243-6.

25. Badyaev AV. Male and female growth in sexually dimorphic species: harmony, conflict, or both? Comments ${ }^{\circledast}$ on Theoretical Biology. 2002;7(1):11-33.

26. Monyeki KD, Sekhotha MM. The relationships between height and arm span, mid-upper arm and waist circumferences and sum of four skinfolds in Ellisras rural children aged 8-18 years. Public Health Nutr. 2016;19(7):1195-9.

27. Krishan K, Kumar R. Determination of stature from cephalo-facial dimensions in a north Indian population. Legal Med. 2007;9(3):128-33.

28. Shah RK, Kanani SD, Patel BG, et al. Estimation of stature from head length in western Indian Gujarati adolescent population. Indian J Clin Anat Physiol. 2018;5(1):42-6.

29. Milašinović R, Popović S, Bjelica D, et al. Body height and its estimation utilizing arm span measurements in female adolescents from northern region in Montenegro. in Book of Abstracts of 4th International Scientific Conference "Exercise and Quality of Life. 2016.

30. Krishan K, Kanchan T, Passi N, et al. Stature estimation from the lengths of the growing foot-a study on north Indian adolescents. Foot. 2012;22(4):287-93.

\section{Publisher's Note}

Springer Nature remains neutral with regard to jurisdictional claims in published maps and institutional affiliations.
Ready to submit your research? Choose BMC and benefit from:

- fast, convenient online submission

- thorough peer review by experienced researchers in your field

- rapid publication on acceptance

- support for research data, including large and complex data types

- gold Open Access which fosters wider collaboration and increased citations

- maximum visibility for your research: over $100 \mathrm{M}$ website views per year

At BMC, research is always in progress.

Learn more biomedcentral.com/submissions 